\title{
E-PORTFOLIOS AS A TOOL TO ENHANCE STUDENT LEARNING EXPERIENCE AND ENTREPRENEURIAL SKILLS
}

\author{
M. Mapundu \\ Department of Epidemiology and Biostatistics \\ University of Witswatersrand \\ Johannesburg, South Africa \\ e-mail: Michael.mapundu@wits.ac.za
}

\section{Musara}

School of Development Studies

University of Mpumalanga

Mbombela, South Africa

e-mail: mazanai.musara@yahoo.com

\section{ABSTRACT}

Increasing digitisation has put pressure on institutions of higher learning around the globe to find effective solutions to better prepare their students for the $21^{\text {st }}$ century world of work. The article presents the findings of a qualitative inquiry into the attitudes, feelings, and experiences of entrepreneurship students in a selected private institution of higher learning on the use of eportfolios as a tool to enhance the learning experience. Data was collected using a combination of focus groups and semi-structured interviews. A thematic analysis conducted for this study revealed five (5) emergent themes on the contributions of e-portfolios in enhancing the learning experiences of the modern-day scholar. The resourcefulness, flexibility, engagement, entrepreneurial skills improvement and collaboration emerged as the outstanding contributions of e-portfolios towards enhancing learning. The emergent themes are in line with the entrepreneurial behaviour, imperative for every $21^{\text {st }}$ century world of work. The value the findings of this study lies in its exploratory utility in exposing the lived-experiences, attitudes, and feelings of modern day students on the role of e-portfolios as a tool to enhance their learning experience and cultivate entrepreneurial behaviour in the modern world of work. Recommendations to explore the technological advantage presented by e-portfolios are presented.

Keywords: e-portfolios, learning experience, entrepreneurship, higher learning, South Africa, digitisation, ICT

\section{INTRODUCTION}

The gradual development and dynamics of the Internet and Web 2.0 technologies is perhaps the most comprehensive enhancement of information technologies that have transpired in the last few years (Haverkamp and Vogt 2015; Raybourn and Regan 2011). Web 2.0 technologies refer 
to a wide array of digital applications that enable interaction, sharing of ideas, collaboration and ubiquity, thus availing a plethora of benefits for users to have an effective and positive learning experience (Yusuf and Tuisawau 2011). Furthermore, these digital applications can be viewed as a central online repository of academic work where students can reflect, engage and become active participants in their own work.

The changing technological spectrum has seen educators around the globe applying reflective ideas and collective learning in academic settings (Yusuf and Tuisawau 2011). Mehtap, Gulcan and Belgin (2010) argued that the socio-cultural, economic and technological changes coupled with new developments in science have increased educational expectations. Raybourn and Regan (2011) state that with the ever-increasing technological developments, there has been an increase in educational technology that accommodates and monitors the performance of users. The authors further point out that several institutions around the world are implementing intelligent educational learning systems and adaptive cognitive practices to improve and enhance students' performance, entrepreneurial skills, and academic experience.

According to Cakan and Mihladiz (2010), there have been a great need for electronic portfolio (e-portfolio) application techniques that are in line with the social constructivism philosophy, entrepreneurial skills, and cognitive learning theory. Tertiary academic institutions have over the past years migrated to the e-portfolio e-learning tool to strengthen learning practices (Kok and Blignaut 2008; Bhattacharya and Hartnett 2007; Parker, Ndoye and Ritzhaupt 2012). E-portfolios have become the key factor in the e-learning process because of the capability to foster students' growth, constructivism and critical reflections on learning. It also has become an ideal vehicle for academic and professional development.

The implementation of e-portfolios at private colleges has become a greater possibility or expectation to enhance the learning experience of students and further improve and strengthen their entrepreneurial skills. Prior to e-portfolios, thus decades before the digital age, assessors, and instructors have used paper-based portfolio systems which were voluminous and tedious. Since the emergence of suitable advancements in technology, e-portfolios have become an important part of students' academic life to exhibit the nature of their work, entrepreneurial skills, and quality of learning.

Jaffer, Ng'ambi, and Czerniewicz (2007) refer to the positive and valuable role Information and Communication Technologies (ICTs) contribute to modern-day education and argue that ICTs are becoming promoters of the learning experience and entrepreneurial skills. The authors elaborate that ICTs play a role in developing potential graduates, improving learning outcomes, entrepreneurial skills, and enhancing and improving the quality of education. Consequently, we need to find ways of integrating e-portfolios into our learning 
processes as a manner of reflecting, presenting and showcasing our competencies, skills, and abilities.

The literature (Caveller 2011; Nicolaidou 2013; Bryant and Chittum 2013; Green, Wyllie and Jackson's 2014; Yastibas and Cepik2015) to date suggests that there has not been much research conducted on the implementation of e-portfolios to enhance the learning experience, better entrepreneurial skills and academic performance at private tertiary institutions. This could be attributed to challenges such as access to the Internet, resources, developed academic skills, policies, and improved information literacy skills (Kok and Blignaut 2008). Bhattacharya and Hartnett's (2007) investigation, to which the main focus was on customised e-portfolio instructional design guidelines aimed at providing learning solutions, shows that little research has been done on how to employ e-portfolios at tertiary institutions to enhance the learning experience of learners. The authors point out that the application of e-portfolios in education for learning and assessment in a global context provides opportunities for freedom of expression by their users.

According to Alam, Chowdhury, Kootsookos and Hadgraft (2015), little research has been done on the use of e-portfolios to mitigate challenges in higher education, including for example, a large group of students taught by one academic staff member. Bryant and Chittum (2013) argue that the use of e-portfolios has the potential of enhancing student learning and improved entrepreneurial skills if applied appropriately. However, there are still substantial gaps in the literature on the adoption and effectiveness of e-portfolios as a learning tool within the field of education. This study, therefore, sought to investigate the attitudes, feelings, and experiences of first-year entrepreneurship students in a selected private institution of higher learning on the use of e-portfolios as a tool to enhance the learning experience.

\section{THE $21^{\text {ST }}$ CENTURY LEARNING EXPERIENCE}

Caveller $(2011,20)$ points out that, "the emergence of the entrepreneurial university has pushed governments and institutions in higher education into research and to implement new systems for measuring performance and efficiency". Furthermore, the author argues that the entrepreneurial university is a new paradigm that resulted in the shift from the traditional university and is focussed more on the engagement of all involved stakeholders in institutions, government, society, and industry to try and provide entrepreneurial benefits in a multi-way negotiated flow of knowledge. The author elaborates that the $21^{\text {st }}$ century universities new model should avail entrepreneurial skills through a structured process implementing eportfolios in preparing learners to become society leaders.

The $21^{\text {st }}$ century is characterised by the increasing use of digital learning tools such as 
mobile devices, social media, and the internet. These $21^{\text {st }}$ century tools have fundamentally shifted the teaching and learning landscape and consequently created a uniquely $21^{\text {st }}$ century learning experience for students. Recent studies (Harris, Jones and Baba 2013; Leow, Neo and Hew 2016) attest that digitisation in the $21^{\text {st }}$ century has facilitated co-construction of knowledge and meaning. As a result, the $21^{\text {st }}$ century student is no longer only expected to memorise text and notes from the professors, but also, are co-constructors of knowledge and meanings. The social networking process facilitated by digital media and the internet has created a space for students to exchange ideas, generate mutual understanding, construct new knowledge and explore new meanings (Leow et al. 2016). Studies such as Chiong and Jovanovic (2012) pointed out that the $21^{\text {st }}$ century classroom has become communities of learning, practice, and collaboration in which students pull their talents, reflect on their opinions and develop new knowledge and meanings. Therefore, a variety of multimedia projects and assignments has become an integral part of the $21^{\text {st }}$ century learning experience.

The design of the $21^{\text {st }}$ century learning experience has been well captured in the constructivist approach. The constructivist approach follows the notion that knowledge cannot be transmitted, but rather it is constructed through meanings making processes that relate to the real-world events (Leow et al. 2016). Therefore, students' real-life experiences play a significant role in shaping their learning experiences in the $21^{\text {st }}$ century. In fact, McLaughlin, Roth, Glatt, Gharkholonarehe, Davidson, Griffin and Mumper (2014) noted that students need to put the personal effort into the learning environment to enhance their learning experience. Less and less teacher prompting and support has been increasingly common in the $21^{\text {st }}$ century learning environment. Thus, learning in the $21^{\text {st }}$ century is a result of social processes and collaborative efforts of students. Leow et al. $(2016,245)$ assert that "The knowledge that is acquired from social processes and collaborative efforts among students set the opportunities for students to apply conception into practice, debate with their peers, and compare their own practice with that of their peers".

The demands of the modern world of work call for collaboration, communication, critical thinking, problem-solving, innovation, reflexive and entrepreneurial thinking and attitudes. Therefore, approaches to enhance these integral skills and experiences are called for. Various tools are being used in the $21^{\text {st }}$ century classroom to achieve the $21^{\text {st }}$ century learning experience. A recently adopted and notable tool is the use e-learning and e-portfolios to foster collaborative and constructivist learning experiences among students (Ellis 2017; Hodgson 2017; Pegrum and Oakley 2017; Hall and Townsend 2017). The following section provides an overview of e-portfolios as an enabler of modern day learning experiences. 


\section{E-portfolios and the modern learning experience}

E-portfolios has become an increasingly popular approach in higher education institutions to facilitate student's reflection on their learning experience and as a centralised assessment of student's learning (Ellis 2017; Pegrum and Oakley 2017). Pegrum and Oakley (2017) further note that students are now able to showcase their accomplishments to potential employers using e-portfolios. Similar sentiments are echoed in Ellis (2017) who argued that e-portfolios have created new possibilities and opportunities for conceptualising, facilitating, structuring, supporting and assuring a modern learning environment. Hodgson (2017) also observed that students can now collectively showcase their curriculum and co-curricular learning experiences using e-portfolios. McKenna, Baxter and Hainey (2017) also applauded e-portfolios as an integrated tool for personal development among students. In fact, Ahmed and Ward (2016) confirmed that students and institutions of higher learning around the world are embracing eportfolios as an important for personal, academic and professional development among students.

E-portfolios have been used extensively in tertiary institutions in teacher preparation programs (Bennett et al. 2016; Strampel, Sibson and Main 2017; Vasinda and Haas 2017; Yastibas and Cepik 2015). The use of e-portfolios in teacher education implies that there is a need to transfer skills acquired by teachers to their own students. In fact, Yastibas and Cepik (2015) noted that several studies such as Goldsmith (2007), Lin (2008) as well as Reese and Levy (2009), among others have expressed the extensive use and benefits of e-portfolios in teacher education.

E-portfolios present an opportunity for students to develop a number of skills that are critical for their career development in the modern world of work. On this viewpoint, Yang, Tai and Lim (2016) argued that e-portfolios engage students in productive learning. Productive learning, according to Yang et al. $(2016,1277)$ is characterised by:

1. "learning motivation driven by intrinsic interests, which is closely related to the deep understanding of subject matter

2. the abilities to self-manage and self-reflect on learning; and

3. the ability to engage in peer-learning for collaborative knowledge building".

Furthermore, the view that e-portfolios provide for self-regulated learning, task authenticity, reflexivity, student autonomy, constructive feedback and above all, inculcating entrepreneurial behaviour, is held in extant literature (Ahmed and Ward 2016; Barbera 2009; Yang et al. 2016). 


\section{E-portfolios and entrepreneurial behaviour}

Entrepreneurship features predominantly in debates around the progress of nations, addressing the triple challenges of poverty, unemployment and inequality as well as advancing the growth of industries. As a result, current trends in institutions of higher learning have seen many institutions adopting teaching and learning methods such as e-portfolios which build creativity and innovation among students (Cuenca et al. 2015). Haverkamp and Vogt (2015) reported innovative integration of technology within e-portfolios of doctoral students. This integration of technology not only foster creativity and innovation among students but also creating a springboard for starting new innovative businesses through entrepreneurship.

The use of e-portfolios has created an opportunity for students to embrace new technologies and innovation in their learning. The adoption of e-portfolios in institutions of higher learning therefore holds a promising potential to inculcate entrepreneurial thinking, acumen, and behaviour. Although Nudelman (2017) in their analysis of e-portfolios of engineering students at one of South Africa's institutions of higher learning, observed that only a few students expressed their intentions to engage in entrepreneurial activity. Nevertheless, the opportunity to collaborate and exercise creativity and innovation through e-portfolios has the potential to inculcate entrepreneurial behaviours. The e-portfolio is now being employed as a tool for identifying and showcasing entrepreneurial skills and as a strategy to try and fight unemployment. The application of the e-portfolio has availed an opportunity for new and established entrepreneurs to reach international boundaries and highlight their key skills and proficiencies (Mozelius, Serey and Escobar 2016).

Literature (for example, Cuenca et al. 2015; Haverkamp and Vogt 2015) suggest that eportfolios are paramount in promoting entrepreneurial behaviours such as creativity, innovation, collaboration, resourcefulness, achievement orientation and risk-taking. The development and promotion of these skills using e-portfolios in institutions of higher education are therefore important.

\section{MODELS OF E-PORTFOLIO BASED LEARNING}

Two notable models that align with e-portfolio based learning are the Jonassen's model of constructivist learning environments and the Gagne's events model. Jonassen's (1999) model follows the constructivist learning approach to facilitate students' construction of new meanings and knowledge through the peer interaction and reflection on their personal experiences. The model views the learning problem and the question of the project as an integral part of the environment with interrelated interpretative and intellectual support mechanisms around it. As shown in Figure 1, modeling, scaffolding and coaching. 


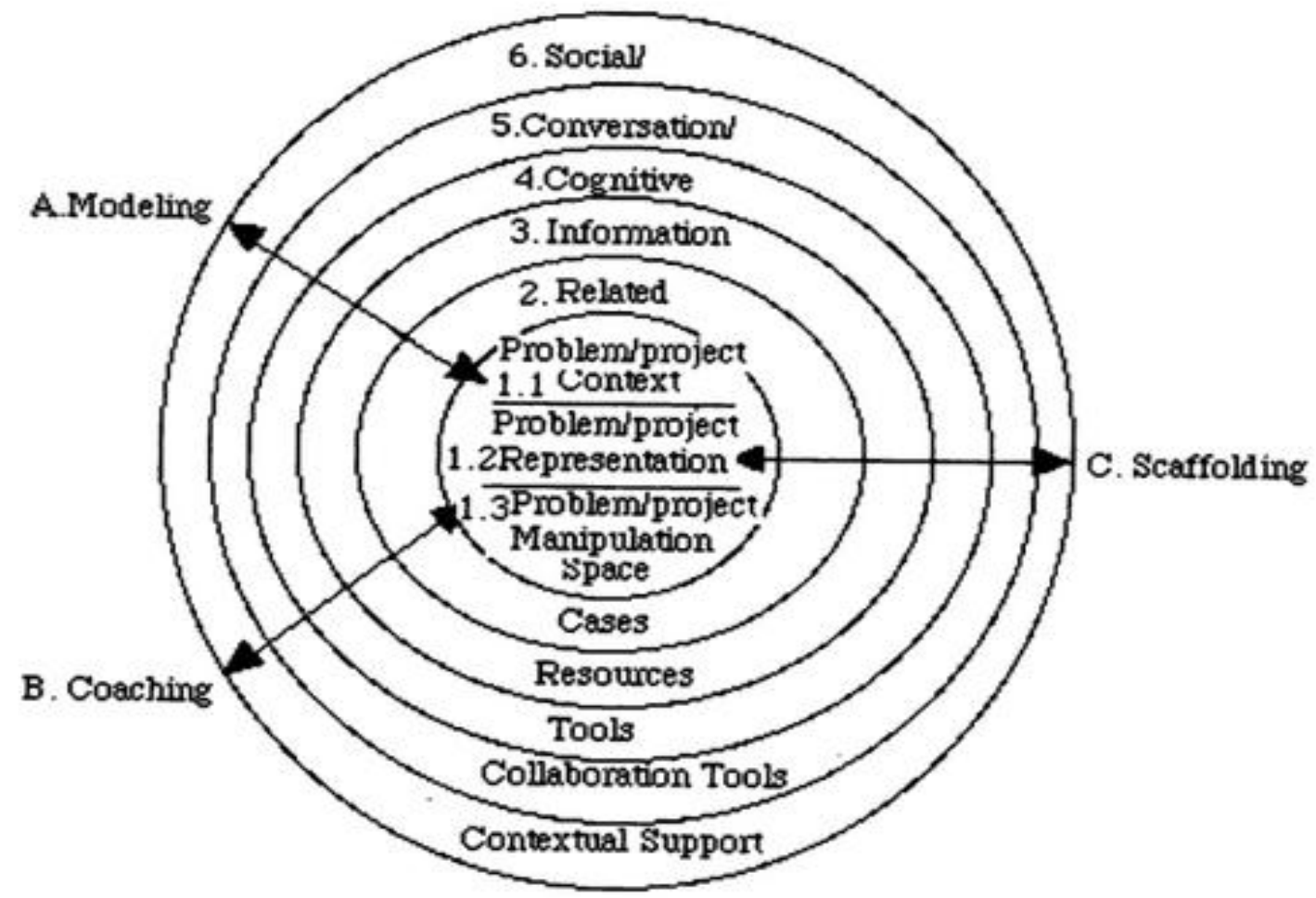

Figure 1: Jonassen's Model of Constructivist Learning Environments (Source: Jonassen 1999, 218).

Gagne's (1965) model explains the conditions of learning which include clear identification of the problem and providing appropriate guidance. The Gagne's events model is used as a tool to organise the information processing and design the instruction that develops student's problemsolving skills. Gagne (1965) proposed nine events of instruction which are critical for the retention and transfer of knowledge to the job situations. The nine events according to Gagne (1965) are:

1. Gain attention

2. Inform learners of objectives

3. Stimulate recall of prior learning

4. Present the content

5. Provide "learning guidance"

6. Elicit performance (practice)

7. Provide feedback

8. Assess performance

9. Enhance retention and transfer to the job

These events can be followed in e-portfolio based learning which is closely tied to creating knowledge, enhancing retention of knowledge and transfer of knowledge to productive uses such as within a job or in starting new businesses. It is for this primary reason that the study at hand sought to investigate the potential of e-portfolios in building entrepreneurial behaviour among students in institutions of higher learning. The following section presents the research 
methodology followed in this study.

\section{RESEARCH METHODOLOGY}

This article is part of a broad study which employed mixed methods, consisting of quantitative and qualitative methodshowever, only qualitative findings are presented. This article therefore adopted an interpretive ontological stance and subjective epistemological stance as the researcher sought to understand how e-portfolios can be used to enhance learning and improve entrepreneurial skills. The focus was on understanding people in a social setting through employing field research to collect and interpret data. The private institution where the research was conducted is highly digitized as it migrated from the traditional learning environment of hardcopy learning content to a new fully Information Technology (IT) based environment where learning takes place through technology enhanced techniques and approaches using tablets and other IT gadgets such as laptop computers. The participants also had good IT skills (as they were the IT cohort) but had never developed or created an e-portfolio before. Therefore because of the high level of IT skills and resources it was easier to teach them how to create an e-portfolio using a user-friendly platform known as Google sites. Empirical data was collected from forty-eight (48) participants during the first semester of 2014 (January to May) at a private tertiary university in Gauteng, South Africa. The study was conducted with an undergraduate IT group at a private tertiary institution in South Africa. The module selected was Networking Technology and comprised novice e-portfolio participant's exposure and experience. The sample of this study consisted of 48 male and female scholars from different ethnic groups with different computer skills, with an age range from 18 to 24-years-old. This study used convenience sampling and stratified sampling techniques to identify the sample groups within the population. This study partially implemented convenience sampling as the subjects were available and the researcher worked at the private institution where the investigation was conducted.

The study furthermore used stratified sampling where sub-populations were identified within the population, and then respondents were selected from these sub-populations through random sampling. The two sub-populations identified were called Group A and Group B. Random sampling was chosen as it assured fair representation; furthermore, the characteristics of each element in the sample were easily observable. This leads to the advantage of increased statistical efficiency through easy access of data to represent and analyse groups, thereby making it easy to apply different methods in the sample groups. A case study and survey through focus group interviews, 48 observations and questionnaire administration were conducted over a period of one semester with scholars registered for the mentioned module.

A pre-implementation investigation was conducted using individual interviews with all 
participants before implementation. And a post-implementation investigation was conducted using focus groups after the implementation of e-portfolios. This conduct was taken in order to observe the attitude of the participants before and after the implementation of e-portfolios. The respondents were trained on the creation of a baseline e-portfolio using Google sites. Both training and development of the e-portfolio online tool were done in less than 5 hours. Participants were asked to include artefacts (pictorial and audio content such as scripts, pictures and audio-visual aids) of their own choice for academic evidence but limited to academic content such as assessments and course outlines. Students were encouraged to employ instructor feedback as well as feedback from their peers for collaborative purposes. During the preimplementation survey, the participants' attitude, feelings, and experiences on e-portfolio application in an academic setting as well as how the e-portfolio tool can enhance and improve entrepreneurial skills were collected and evaluated. In the pre-implementation survey, for example, the participants were asked questions such as; "What are your opinions about the use of e-portfolios?" Qualitative data were obtained from post-event (after implementation of the e-portfolio tool) semi-structured interviews and focus group interviews. Participants were divided into groups at random for focus group interviews. The post-event interview included questions such as, "Do you think there have been any improvements in your academic work using e-portfolios? List a few areas that have been affected." Individual interviews took a maximum of 30 minutes each and focus group discussion took approximately one hour. All forty-eight (48) participants were involved in both semi-structured individual interviews and focus groups. To minimise bias, the interviews and focus groups were conducted by the fieldworkers, other than the instructor. To facilitate easier and manageable focus group discussions, participants were randomly divided into two groups (Group A and Group B). The interviews were audio recorded and transcribed. Thematic analysis was employed in analysing qualitative data. Trustworthiness for qualitative data and justification for credibility, dependability, transferability, and confirmability were assured in this study using member checks, reflexivity as well as rigour in the interpretations of the data. In addition, prior to the commencement of data collection, the project proposal was assessed and ethical approval was obtained from the Research Ethics Committee (REC). Only one researcher analysed the data. However, to enhance the reliability and trustworthiness of the findings, interview transcripts and interpretations were shared with participants to confirm if they were a true reflection of their responses before being finalised. Where disagreements arose, these were reconciled by aligning to the participant's views.

\section{RESEARCH FINDINGS}

Thematic analysis was performed to analyse the collated responses and focus group data. 
According to Braun and Clarke (2006), the first phase to become familiar with the data is through a process known as immersion, meaning repeated active reading. Verbal data, obtained and recorded from the focus group interview, were transcribed through interpretative data analysis, employing various conventions of speech to text. Following this, codes were generated using a data-driven approach with the focus on the data. A systematic approach was deployed to the data set. Themes (data categories which have been coded and collated) began to emerge as the researcher progressed. The themes were then refined through extensive reviewing, where after each theme was defined and named; this created the initial coding scheme. Through continuous evaluation, five final themes emerged, namely: resourcefulness, flexibility, engagement, collaboration, and entrepreneurial skills development. The themes are shown in Table 1 and discussed next.

Table 1: Themes

\begin{tabular}{|c|c|c|c|c|c|}
\hline Themes & $\begin{array}{l}\text { Resource- } \\
\text { fulness }\end{array}$ & Flexibility & Engagement & Collaboration & $\begin{array}{c}\text { Entrepreneurial skills } \\
\text { development }\end{array}$ \\
\hline Codes & $\begin{array}{l}\text { - Educative } \\
\text { - Informative } \\
\text { - Helpful } \\
\text { - } \text { Assess } \\
\text { knowledge }\end{array}$ & $\begin{array}{l}\text { - Anyone } \\
\text { - Anywhere } \\
\text { - Any time } \\
\text { - Always have } \\
\text { - access } \\
\text { - Convenient }\end{array}$ & $\begin{array}{l}\text { - fun, } \\
\text { interesting } \\
\text { and } \\
\text { informative } \\
\text { - delightful } \\
\text { and } \\
\text { informative } \\
\text { - peer } \\
\text { exchange }\end{array}$ & $\begin{array}{l}\text { - Learning and } \\
\text { communication } \\
\text { skills with friends } \\
\text { - peers to } \\
\text { communicate easily } \\
\text { and to access data } \\
\text { easily } \\
\text { - interact with } \\
\text { professionals }\end{array}$ & $\begin{array}{l}\text { - } \text { entrepreneurial activity } \\
\text { - } \text { monitoring of work } \\
\text { - entrepreneurial skill } \\
\text { development } \\
\text { - creativity and } \\
\text { innovation } \\
\text { - self-analysis, learning } \\
\text { and communication } \\
\text { skills }\end{array}$ \\
\hline
\end{tabular}

\section{Resourcefulness}

A recurring theme that emerged was the helpfulness/resourcefulness of e-portfolios as a learning tool and enhancer of entrepreneurial skills. Participants stated that e-portfolios are useful in identifying their strengths and weaknesses and that this may also help them in reflecting on their own learning.

Participant 10 stated that e-portfolios are "productive in my studies". Participant 12 (Group A) stated that e-portfolios are "cool and educative" and these sentiments were echoed by participant 11 (Group A), who pointed out that e-portfolios "are delightful and informative". E-portfolios make it possible to identify one's strengths and weaknesses as stated by participant 13 (Group A) who argued that "e-portfolios are a good way to help students assess their knowledge on a particular subject to improve from their mistakes". This was supported by participant 15 (Group A) who stated that "they are very useful in identifying my strengths and weaknesses". Participant 1 (Group A) stated that "e-portfolios are helpful”, thus introducing e- 
portfolios will be a good idea. Participant 13 (Group A) argued that there has been an improvement in academic work through the implementation of e-portfolios stating that "it has impacted the way we study and how we analyse work and improved areas that we have to focus on". Participant 10 (Group B) stated that "e-portfolios are great to keep track of work and to view strengths and weakness", thus it can improve marks as supported by participant 2 (Group A) who indicated that maintaining an e-portfolio "is a good way to improve my academic performance".

The above highlights the capability of self-monitoring and evaluation through scholarcentred learning as discussed in the literature. This mirrors the concept of entrepreneurial skills and enriched learning experiences that enhance academic performance. It offers a platform to evaluate and reveal own competencies as echoed by participant 15 (Group A) who commented that e-portfolios "make me reflect on my learning".

\section{Flexibility}

Participants reflected on the ubiquity of e-portfolios as one can easily access and use it from anywhere. Participants attributed more significance to the ready accessibility of e-portfolios that makes it possible to submit work from anywhere, anytime. Participant 2 (Group A) stated that e-portfolios "are a good idea because work can even be submitted from home". This was reinforced by participant 14 (Group A) who pointed out that e-portfolios "are good because you can check them whenever you feel like and show it to your parents". Participant 10 (Group B) stated that "anyone can do it from anywhere". This notion is supported by participant 3 (Group A) who stated that "it creates a more comfortable working area because I can submit my work in the comfort of my room".

The ubiquity of e-portfolios can assist in enhancing the learning experience of students and subsequently contribute to improving academic performance and grades. This notion is supported by participant 13 (Group A) who stated that he/she will continue maintaining an eportfolio "because it is helping me with improving my grades and my studying". Furthermore, participant 12 (Group A) agreed with this notion and pointed out that e-portfolios "allow students to progress academically".

It was found that e-portfolios streamline job processes, thus sponsors and parents and all stakeholders involved can keep up to date with the scholar's' progress through the e-portfolio tool. Participants stated that the ubiquity of e-portfolios gives them an opportunity to receive timeous feedback, thus positive constructivism. Another important aspect mentioned was that of easy access to information as well as the accumulation of basic computer skills throughout the development and maintenance of e-portfolios. Participant 9 (Group B) said that e-portfolios 
are a good idea "because I always have access and backup of documents as a soft copy". Remote access was a major highlight of this study. Participant 14 (Group B) stated that e-portfolios are "very convenient because you can view it remotely anytime and update it".

\section{Engagement}

Participants acknowledged that e-portfolios are appealing and motivate one to become an active scholar. Once a scholar becomes an active learner, he/she is self-motivated and grows in eagerness to learn, thus obtaining better results through enriched experiences. Participant 7 (Group A) stated that they are "so much fun, interesting and informative". The above concept is supported by participant 11 (Group A) who pointed out that "of course, e-portfolios are delightful and informative". Through the use of e-portfolios, students can become active in class as this has a positive impact on recalling/remembering learned concepts, thus positive constructivist; students eventually become logical thinkers as evidenced by participant 1 (Group A) who stated that e-portfolios improve "memory and my communication with my fellow colleagues".

Participant 12 (Group A) stated that e-portfolios are "cool and educative". This further highlights the concept of active engagement that is core to scholarly enhancement. Another interesting finding was that e-portfolios can assist students in scheduling work to meet deadlines. It was found that e-portfolios can be used as a tool to evaluate oneself from a scholarly perspective. Participant 3 (Group B) stated that "I enjoyed viewing my peer's eportfolio".

\section{Collaboration}

One of the major advantages of e-portfolio creation and maintenance is effective collaboration and communication. This was indicative development of the study as almost all respondents acknowledged the need for effective communication channels to share ideas, group work, and any school-related materials through e-portfolios. The respondents acknowledged that the use of an e-portfolio precipitates effective communication and collaboration. Participant 1 (Group A) stated that "it is a sufficient tool that can really help me in my learning and communication skills with my friends". An e-portfolio can also be used for collaborative purposes. Participants also stated that by communicating with peers they can share ideas and thereby improve their academic performance and experience. This enhances collaborative workspace whereby students can interact online and define the new era of online group work. Participant 3 (Group A) stated: "I think it allows students and peers to communicate easily and to access data easily". Participants noted that if e-portfolios are put to good use, it can become a good platform for 
sharing ideas and collaboration. Participant 7 (Group A) stated that e-portfolios are "a good communication medium".

An important element of e-portfolios is that it helps with the interaction of involved stakeholders, thereby affording instant feedback. Participant 11 (Group B) stated that eportfolios are a good way to share ideas and achievements as well as interact with other intellects. This is supported by participant 9 (Group B) who argues that comments from fellow students avail an opportunity for improvement. This induces peer review as respondent 11 (Group B) commented: "Viewing other people's e-portfolios has given me information and ideas to use in my own work".

It was found that interactivity within an e-portfolio will assist students in an on-going process, thereby enhancing their academic performance and experience. These sentiments were echoed by participant 11 (Group B) who commented that I will continue using an e-portfolio "because the interactivity within an e-portfolio will assist me in my work on an ongoing basis".

An important aspect raised was that e-portfolios make group work easier. Participant 15 (Group B) agreed that e-portfolio implementation is "a good way to communicate with other students. It will help me with classwork, make group work easier". This participant further argued that through e-portfolios, "students can interact with other students and help each other".

Participant 14 (Group B) argued that the application of e-portfolios can aid in effective monitoring and improvement of academic work through effective feedback: "Submitting work and receiving feedback has been much faster". Participant 8 (Group A) stated that e-portfolios "are useful and allow people to view and interact with professionals". This is further supported by participant 14 (Group A) who argued that e-portfolios make it possible to communicate with fellow students. Participant 6 (Group B) also supported the notion of collaboration and communication explaining that "it is a way to upload your progress on work and ask friends to help you out", adding; "we can discuss ideas with friends". Participant 9 (Group B) further cemented this by stating that the use of e-portfolios allows one "to share your portfolio with other users on the internet". Participant 11 (Group B) is in agreement with the above respondents in that "they make it easy to store and share academic work".

\section{Entrepreneurial skill improvement}

This theme formed the core of the research project debate. There were various comments from participants on how e-portfolios have improved their entrepreneurial skills academically, socially and otherwise.

The ability to showcase skills on a global scale was seen by many respondents as an opportunity to increase their chance of venturing into entrepreneurial activity. The results of 
the qualitative analysis suggest a myriad of significant entrepreneurial benefits through the implementation of e-portfolios. There was a mutual consensus among the participants of this study that leads to the deduction that e-portfolios are effective academic tools that are resourceful in entrepreneurial skills and education improvement through practical experiences. Abrami and Barret (2005) elaborate on increased scholar awareness through the implementation of e-portfolios; thus, scholars become engaged and active in the learning process with an enhancement in self-motivation thereby identifying the potential for venturing into entrepreneurial activities. This notion is supported by participant 9 (Group A) who pointed out that "e-portfolios increase self-confidence and self-motivation and one can easily develop skills that are needed for entrepreneurial development".

In addition, participant 13 (Group A) reaffirmed that "the benefits of e-portfolios could contribute to the enhancement of learning experiences and opportunity to increase our chance of venturing into entrepreneurial activity". The sentiments are echoed by participant 7 (Group B) who pointed out that 'e-portfolios' implementation is prevalent in education and enables the tracking or monitoring of work more than what supervised learning can offer". Entrepreneurial development is further cemented by participant 3 (GroupB) who pointed out that "e-portfolios allow collaboration and sharing ideas where scholars can reflect on their own learning and become engaged in the whole learning process thereby gaining confidence in increasing their chance of venturing into entrepreneurial activity". Participant 10 (Group A) mirrors the former and affirms that "e-portfolios afford the opportunity of scholar reflection and growth over time", implying that there is a great possibility for learners to realize their potential of venturing into entrepreneurial activity. Participant 20 (Group B) acknowledged that "e-portfolios allows me to reflect on my entrepreneurial skill development and precipitates a platform for continuous progression in relation to time". Notwithstanding, participant 17 (Group B) who mentioned that "e-portfolios improve entrepreneurial organization and presentation skills".

One important aspect the researcher noticed was that e-portfolios enable persons to become technologically advanced. Participant 1 (Group B) commented that e-portfolios are a good idea as "education is moving forward technologically, helping develop the skills that are needed for entrepreneurial skillset in our country". This notion supports technological competence, implying that the creation and maintenance of e-portfolios is a parallel way of becoming computer literate, hence easy tool to manage entrepreneurial data.

Creativity and innovation were seen by some of the participants as an important benefit drawn from the use of e-portfolios. This notion is clearly expressed by participant 6 (Group A) who states that "e-portfolios enable students to be creative and innovative, thus they avail a plethora of benefits among many and allow us to become cognitive apprentices". E-portfolios 
are technological tools that precipitate independence, self-motivation, and creativity and give one the confidence of experimenting, and this enables learners to become more creative to initiate new ideas. Furthermore, learners instill the capability of self-monitoring, student autonomy, and self-evaluation through scholar-centered learning. There is a revived sense of responsibility and ownership when using e-portfolios (Little 2009, cited in Chau and Cheng 2010). This idea mirrors the concept of enriched learning experiences that enhance academic performance. E-portfolios offer a platform to evaluate and reveal own competencies as echoed by participant 15 (Group A) who commented that e-portfolios "make me reflect on my learning through creativity and innovation". Participant 1 (Group B) commented that e-portfolios are a good idea as education "is moving forward technologically, helping us to be innovative and experiment new ideas to develop the learning process in our country". These sentiments were echoed by participant 7 (Group B), stating; "I think that the use of e-portfolios will enhance entrepreneurial innovation and the way that learning and business take place, considering the fact that we are now in a technological era".

Additional to the sentiments given by the participants, it was held that collaboration towards coming up with new ideas and reaching out a to wider target audience is an important entrepreneurial skill developed from the use of e-portfolios. And that the opportunity to collaborate enables students to identify like-minded people and potential business partners, this understanding was echoed by participant 8 (Group A) who points out that:

“... e-portfolios enable them (learners) to collaborate towards coming up with new business ideas and make it possible for us (learners) as potential entrepreneurs to develop the ability to gather and harness resources as well as building skills and attitudes towards starting their own businesses."

Another important element of e-portfolios is that it helps with the interaction of involved stakeholders, thereby affording instant feedback. Participant 11 (Group B) stated that "eportfolios are a good way to share ideas and achievements as well as interact with other intellects and business partners to foster long-lasting entrepreneurial relationships".

An essential aspect raised was that e-portfolios make group work easier. Participant 15 (Group B) agreed that e-portfolio implementation is "a good way to communicate entrepreneurial ideas with other scholars". Participant 8 (Group A) stated that e-portfolios "are useful and allow people to view and interact with professionals and build business networks". This understanding is further supported by participant 14 (Group A) who argued that "eportfolios make it possible to communicate with fellow entrepreneurs and get positive feedback in real-time". Participant 9 (Group B) further cemented this by stating that "the use of e- 
portfolios allows one to share your portfolio with other business associates on the internet".

Most participants in this study pointed out that e-portfolio provided them with a platform to reflect and do an introspection on their potential entrepreneurial journey. E-portfolios offer a platform to evaluate and reveal own competencies as echoed by participant 15 (Group A) who commented that e-portfolios "make me self-reflect and give me initial entrepreneurial skills and experiences that I can employ in business". This reflection on entrepreneurial skills and experience was supported by participant 13 (Group A) who stated that e-portfolios are "a good way to help scholars assess their knowledge on entrepreneurial skills and improve from past mistakes", and further reverberated by participant 1 (Group A) who stated that "an e-portfolio is a sufficient tool that can really help me in self-analysis, learning and communication skills, thus improving my entrepreneurial skillset".

\section{Drawbacks of e-portfolios}

Despite the magnitude of positive feedback received from participants on the use of eportfolios, there were a few discerning voices that pointed out negatives aspects of e-portfolios. Participants noted that there was excessive time and resource pressure in developing the eportfolios, observing that there was limited time for them to complete the e-portfolios. The resource constraints faced by participants was additional to the negative perceptions and experiences to e-portfolios. The rest of the participants who identified negative aspects of eportfolio's noted that e-portfolios are vulnerable to cyber-attacks and that this may affect the future use of e-portfolios.

This research study found that not all of the respondents have validated the importance of e-portfolios as a new learning tool. This was evidenced by the negative responses the researcher received. Going forward, there is a need to enlighten students on the necessity to have a central archive of information that will afford collaboration and effective communication, thus creating a learning environment that is flexible and ubiquitous. There is, therefore, a need to motivate and cultivate a culture of awareness towards employing e-portfolios to enhance the learning experience and performance of students. In fact, the noted weaknesses in e-portfolio implementation can be addressed by adopting Jonassen's Model of Constructivist Learning Environments (Jonassen 1999) as well as applying Gagne (1965)'s model that explains the conditions of learning.

\section{DISCUSSION}

This section provides an in-depth discussion that is logical, coherent and related to literature from previous studies. An in-depth analysis of the participants' responses, supported by e- 
portfolio evidence and reflective engagement, validates a wide spectrum of benefits discussed in previous literature with the main emphasis on scholar-centered learning and entrepreneurial skills. Moreover, we pay particular attention to the attitudes and feelings on e-portfolios as a tool to enhance student learning experience and entrepreneurial skills as perceived by learners from a private institution. In qualitative research, the emphasis is on opinions, attitudes and feelings of the participants. The themes identified re-affirm that e-portfolio implementation has a positive impact on the attitudes and feelings of the participants as the learners, attesting that e-portfolio implementaion improved their entrepreneurial skills over time. Furthermore, the approach of e-portfolios as a technological tool creates a self-regulated learning environment which is concerned with the implementation of models that improve the attitudes and feelings of the learners in terms of cognition, motivation and behavior in a classroom environment. Selfregulating scholars are dynamic and actively participate and competently manage their own learning in a variety of ways (Pintrich 2000). Scholars are self-regulating to the level that they are perceptive, enthusiastic and interactively dynamic, active participants in their learning (Zimmerman 1989). The attitude and feelings of participants are discussed and emerged into themes.

Previous literature (Damoense 2003; McDermott and Gallagher 2011; O'keeffe and Donnelly 2013) elaborates on the enriched scholar experiences and effective feedback from assessors through the implementation of e-portfolios. Abrami and Barret (2005) elaborate on increased scholar awareness through the implementation of e-portfolios; thus, students become engaged and active in the learning process with an enhancement in self-motivation .

The identified themes reaffirm the benefits of e-portfolios and could contribute to the enhancement of learning experiences and the performance of students. Parker et al. (2012) state that e-portfolios' implementation is prevalent in education and enables the tracking or monitoring of work more than what supervised learning can offer. The authors further elaborate on the concept of collaboration and sharing ideas where students can reflect on their own learning and become engaged in the whole learning process. Parker et al. (2012) finds that more emphasis should be placed on the need to address the scope and enlightenment of the use of eportfolios into curricula. Irregardless of this finding, Parker et al. (2012) managed to identify further benefits such as improvement of organisation and presentation skills of their work. There was more value added to the work of the participants.

Parker et al. (2012) noted the important aspects of e-portfolios enabling students to advance their technological skills since the creation and maintenance of e-portfolios is technologically oriented. Chau and Cheng (2010) elaborate on the concept of "cognitive constructivism" as a way in which students define new knowledge and experiences based on 
personal judgment rather than passive reception, implying that students can experience authentic learning that is real through the implementation of e-portfolios, and that they should strive to improve their understanding from time to time. Hartnell-Young et al., (2007, cited in Chau and Cheng 2010) in their study state that e-portfolios allow students to collect, organise and present artifacts for different audiences and at varying times.

Alexiou and Paraskeva (2010) in their paper suggest that students should be self-regulated and be active participants to become self-independent. The authors further deliberate on the concept of students being intellectual, motivationally active participants in their own learning, which is similar to what this study found, namely that through e-portfolio use, students become actively engaged and part and parcel of the entire process. This defines a new element of selfmotivation and scholar-centered learning, which is key to scholar enhancement and improved academic experiences and performance. Yusuf and Tuisawau (2011) discovered that e-portfolio use had increased positively over the past decades and that among numerous benefits is the positive attitude of students towards its implementation as a learning tool . The authors further elaborate on the usefulness of e-portfolios as a learning tool and how it helps students to keep track of their own progress, and guide, develop knowledge and enhance them in their lifelong learning.

Akcil and Arap (2009) in their study discovered a positive perception from students in the use of e-portfolios. The authors found a positive element of effective communication, which is key to enhancement. They advocate that "learning is permanent" where e-portfolios are employed thus developing a lifelong learning. Additionally, the authors mention scholarcentered learning where students can monitor and control themselves through e-portfolios. Key to their findings is the rise in self-confidence and security in the learning process, where evaluation techniques are employed with e-portfolios. This highlights a key concept of scholar engagement whenever e-portfolios are used as a learning tool. Furthermore, Akcil and Arap (2009) highlighted the acquiring of computer skills through e-portfolio creation and maintenance.

Meyer, Abrami, Wade, Aslan and Deault, (2010) indicate that e-portfolios are used for lifelong learning and encourage improvement, personal growth, and development. The authors find that e-portfolios are helpful to students who tend to work slower than the average scholar, through the undertaking of authentic tasks the students develop and reflect on their abilities. Moreover, Meyer et al. (2010) argue that through e-portfolio implementation, students become engaged and can easily overcome their academic shortcomings through refinement, positive feedback and collaboration with peers via a well-defined metacognition platform. Flexibility is highlighted in their paper where it is indicated that the element of remote access and ubiquity 
allow easy access from involved stakeholders. Based on the above analysis and related literature it can be deduced that e-portfolios are imperative and enhance scholar performance and experiences. The literature suggests the conceptualisation of e-portfolio components as highlighted above and as a new paradigm to scholar assessment and the pedagogical potential that e-portfolios come with. Thus, with technological advancement, there is a need to do away with traditional paper-based portfolios and integrate new e-portfolios into the learning environment. E-portfolios are being implemented worldwide at a very fast rate and we are moving towards e-assessment. The analysis above suggests a myriad of significant benefits through the implementation of e-portfolios. There is a mutual consensus among the participants of this study that leads to the deduction that e-portfolios are effective academic tools that are resourceful in education improvement and experiences.

An progressive finding was that e-portfolios support ubiquity; participants felt that with e-portfolios, it is possible to submit work anywhere and anytime which could help improve academic performance and grades. It was also found that e-portfolios streamline job processes therefore allowing sponsors, parents and other involved stakeholders to keep up to date with students' progress through the e-portfolio tool. E-portfolio can also be used for collaborative purposes; participants indicated that by communicating with peers on e-portfolios, ideas can be shared, thereby improving academic performance and experience. This also enhances collaborative workspace whereby students can interact online and define the new era of online group work.

Participants agreed that the e-portfolio can be effectively used in learning as they help in interpersonal communication, reflection, collaboration, engagement, assessment, and learning. This is evidenced by the survey results. Mason, Pegler and Weller, (2004) also found that an eportfolio can be used effectively in pursuit of lifelong learning and even developing curriculum vitae, thus it can possibly become an online digital age curriculum vitae. However, it was noted that some participants stated that e-portfolios are time-consuming and tedious to maintain.

From the findings of Siemens, Mcauley, Stewart and Cormier, (2010) it was held that higher education institutions have to make a transition from paper-based portfolios to electronic portfolios if they are to improve the quality of education and provide students with a productive learning experience. This investigation noted a significant improvement in the maintenance of e-portfolios as some students improved on presentation, organisation and consequently their grades. The learners became more active and improved in terms of participation. According to findings by Lorenzo and Ittelson (2005), the use of the e-portfolio had assisted students to become critical thinkers when a two-way process between students and instructor reflections on learning and feedback was included in the course, students also improved on collaboration. 
The authors' findings imply that e-portfolio's made group work easier and therefore the sharing of ideas was achieved effortlessly. The interactive and connectedness of the themes observed in this study provide a springboard for a productive learning experience and the development of entrepreneurship.

Figure 2 shows the schematic presentation of the findings of this study. The possible interrelationships between themes are evidence in the analysis of the findings. In both the focus groups and individual interviews, participants showed a connecting thread amongst the themes. Participants who highlighted the resourcefulness of e-portfolios also attested that e-portfolio enhanced their entrepreneurial skills. Similarly, the same participants who attested to the collaboration skills built into the use of e-portfolios pointed at the potential engagement with peers as well as identification of like-minded people and/or partners to start a business with, thereby creating a potential for entrepreneurial activity. These interrelationships are shown in Figure 2 and require further testing using quantitative studies. The bidirectional arrow resembles an interrelationship between two themes, for example; for one to have entrepreneurial skills there has to be engagement in the process.

A very important finding of this study is that e-portfolios are instrumental in facilitating and providing opportunities for the development of entrepreneurial skills among students. The value of e-portfolios as a tool as an enabler of entrepreneurship is expressed in literature. Mozelius et al. (2016) argue that entrepreneurs around the globe have difficulties in showcasing their skills, collaborating and reaching their target audience. Furthermore, the authors suggest that the e-portfolio is a great and effective tool to employ to address the earlier notion. In their findings, they found the e-portfolio tool to be effective in strengthening entrepreneurial ideas as well as collaboration. Horris and Liguori (2016) point out that there is great need to encourage students to become reflective and introspective whilst documenting their self-critical reflection on the application of the e-portfolio tool. Furthermore, they argue that there is a need for the users of the e-portfolio to create a valuable relationship with self, entrepreneurship and the world in order to set up potential businesses. The authors further argue that much can be achieved and enhanced if learners can employ a detailed, well-structured and quality eportfolio. Among a vast array of benefits is that students have the opportunity to "reflect critically and develop through experiences abilities in analysis, reflection, critique, creation, and implementation while demonstrating mastery of particular entrepreneurial competencies such as opportunity recognition and, risk mitigation and resource leveraging" (Horris and Liguori 2016, 174). 


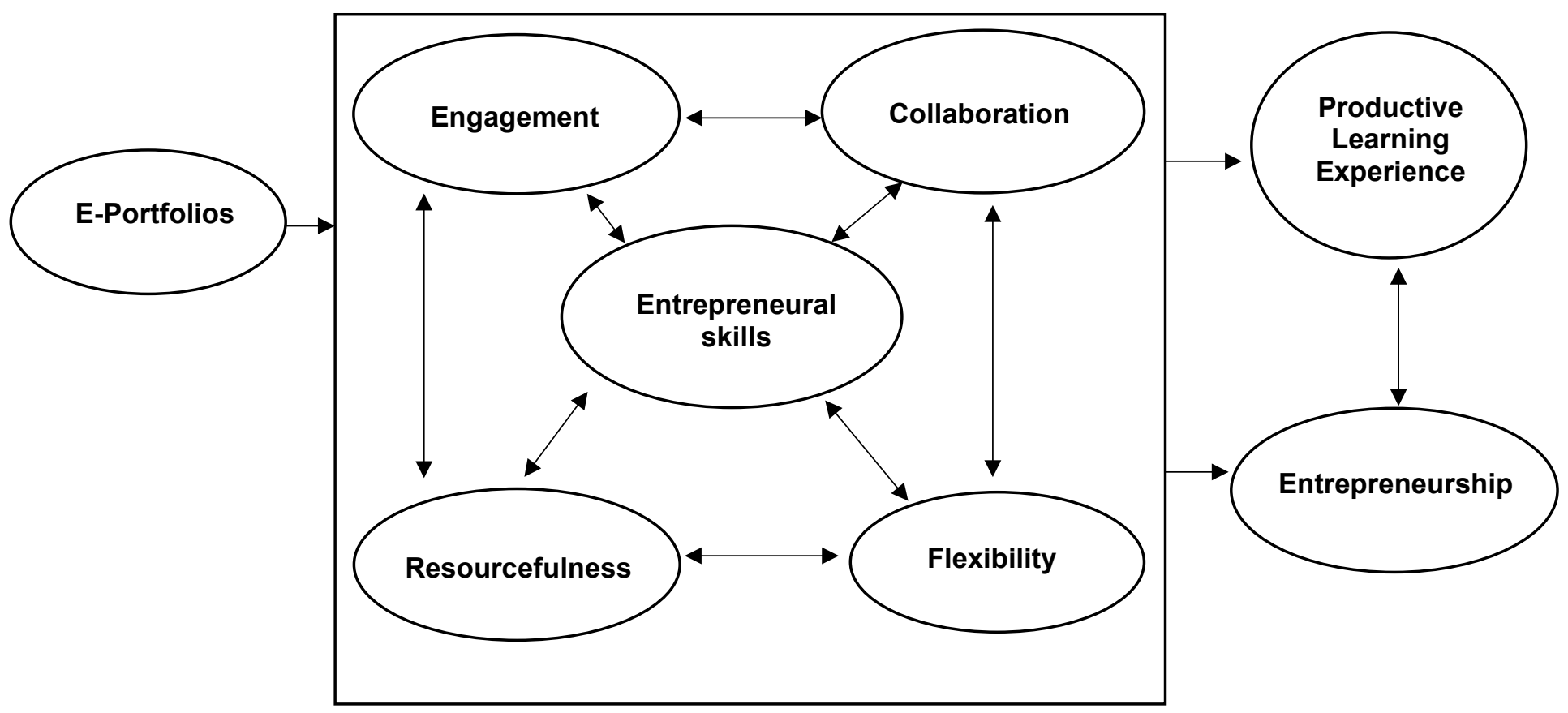

Figure 2: E-portfolios, Learning Experience, and Entrepreneurship

This article affirms that e-portfolios afford the opportunity of scholarly reflection and growth over time. The participants of this study acknowledged that e-portfolios allowed them to reflect on learning and provided them with a platform for continuous progression in relation to time management and academic growth over time. Despite the noted benefits of e-portfolios presented in this study, it is important to note the limitations of this study. Firstly, the fact that perceptions and attitudes and not the actual behaviour was observed, presents a limitation as to whether the changes in perceptions and attitudes resulted in changes in academic performance.

\section{CONCLUSION}

Electronic portfolios are increasingly becoming part of the higher education experience of students. This trend looks set to spread beyond early adopters to encompass many, if not all higher education institutions. For the e-portfolio to be considered an effective and useful learning tool, students need to be actively engaged with their own e-portfolios.

This study has contributed to the body of knowledge on how students at private tertiary institutions in South Africa can become actively engaged in the implementation and application of e-portfolios, and how the use of e-portfolios can be integrated into learning and assessment through effective interpersonal communication and collaboration to enhance the learning experience of students. The final deduction of this study can conclusively be summarised as follows: 
"Through the exploration of literature to date and research conducted at a private tertiary institution in South Africa, a technologically advanced e-portfolio platform employed at this institution significantly enhanced a productive learning experience and entrepreneurial skills of students registered for the Information Technology programme. Improved scholarly communication, sharing of ideas, collaboration, flexibility, critical reflection on own work, identifying strengths, keeping track of progress are also notable contributions drawn from the use of e-portfolios."

It is recommended, considering limitations of this study, further longitudinal studies are important to track whether the use of e-portfolios results in actual behavioural changes such as entrepreneurial activity and improved performance.

\section{REFERENCES}

Abrami, P. C. and H. Barrett. 2005. Directions for research and development on electronic portfolios. Canadian Journal 31(3): 1-15.

Ahmed, E. and R. Ward. 2016. Analysis of factors influencing acceptance of personal, academic and professional development e-portfolios. Computers in Human Behavior 63: 152-161.

Akcil, U. and I. Arap. 2009. The opinions of education faculty scholars on learning processes involving e-portfolios. Paper presented at the World Conference Education Science held on 5 January in Nicosia, North Cyprus.

Alam, F., H. Chowdhury, A. Kootsookos and R. Hadgraft. 2015. Scoping e-portfolios to engineering and ICT education. Procedia-Engineering 105(2015): 852-857.

Alexiou, A. and F. Paraskeva. 2010. Enhancing self-regulated learning skills through the implementation of an e-portfolio tool. Procedia - Social and Behavioural Sciences 2(2): 30483054.

Barbera, E. 2009. Mutual feedback in e-portfolio assessment: an approach to the netfolio system. British Journal of Educational Technology 40(2): 342-357.

Bennett, D., J. Rowley, P. Dunbar-Hall, M. Hitchcock and D. Blom. 2016. Electronic portfolios and learner identity: An ePortfolio case study in music and writing. Journal of Further and Higher Education 40(1): 107-124.

Bhattacharya, M. and M. Hartnett. 2007. E-portfolio assessment in higher education. Paper presented at the 37th Frontiers in Education Conference, 10-13 October, Milwaukee, New Zealand.

Braun, V. and V. Clarke. 2006. Using thematic analysis in psychology. Qualitative Research in Psychology 3(2): 77-101.

Bryant, L. and J. Chittum. 2013. ePortfolio effectiveness: An ill-fated search for empirical support. International Journal of ePortfolio 3(2): 89-198.

Cakan, M. and G. Mihladiz. 2010. How portfolio use affects scholars' learning and their attitudes toward 6th-grade science lesson. International Online Journal of Educational Sciences 2(2): 362-377.

Caveller, V. 2011. Portfolios for entrepreneurship and self-evaluation of higher education institutions. Procedia Social and Behavioural Sciences 12(2011): 19-23.

Chau, J. and G. Cheng. 2010. Towards understanding the potential of e-portfolios for independent learning: A qualitative study. Australian Journal of Educational Technology 26(7): 932-950.

Chiong, R. and J. Jovanovic. 2012. Collaborative learning in online study groups: An evolutionary game theory perspective. Journal of Information Technology Education: Research 11: 81-101.

Cuenca, L., M. Fernández-Diego, M. Gordo, L. Ruiz, M. M. E. Alemany and A. Ortiz. 2015. Measuring competencies in higher education. The case of innovation competence. In Sustainable Learning in Higher Education, 131-142. Springer International Publishing. 
Damoense, M. 2003. Online learning: Implications for effective learning for higher education in South Africa. Australian Journal of Educational Technology 19(1): 25-45.

Ellis, C. 2017. The importance of e-portfolios for effective student-facing learning analytics. In $E$ Portfolios in Higher Education, 35-49. Springer Singapore.

Gagne, R. 1965. The conditions of learning. $1^{\text {st }}$ Edition. New York: Holt, Rinehart \& Winston.

Goldsmith, D. J. 2007. Enhancing learning and assessment through e-portfolios: A collaborative effort in Connecticut. New Directions for Student Services 2007(119): 31-42.

Green, J., A. Wyllie and D. Jackson. 2014.Electronic portfolios in nursing education: A review of the literature. Nurse Education in Practice 14(2014): 4-8.Hall, J. M. and S. D. C. Townsend. 2017. Using critical incidents and E-Portfolios to understand the emergent practice of Japanese studentteachers of English. Teaching and Teacher Education 62: 1-9.

Harris, A., M. Jones and S. Baba. 2013. Distributed leadership and digital collaborative learning: A synergistic relationship? British Journal of Educational Technology 44(6): 926-939.

Hartnell-Young, E., C. Harrison, C. Crook, G. Joyes, L. Davies, T. Fisher, R. Pemberton and A. Smallwood. 2007. The impact of e-portfolios on learning. http://dera.ioe.ac.uk/1468/7/becta_2007_ eportfolios_summary_Redacted.pdf (Accessed 12 March 2014).

Haverkamp, J. J. and M. Vogt. 2015. Beyond academic evidence: Innovative uses of technology within e-portfolios in a Doctor of Nursing Practice program. Journal of Professional Nursing 31(4): 284 289.

Hodgson, P. 2017. Student e-portfolios: Unfolding transformation in university life in General Education Program. In E-Portfolios in higher education, 171-181. Springer Singapore.

Horris, M. H. and E. Liguori. 2016. Annals of Entrepreneurship Education and Pedagogy. Cheltenham UK, Northampton, MA, USA: Edward Elgar Publishing.

Jaffer, S., D. Ng'ambi and L. Czerniewicz. 2007. The role of ICTs in higher education in South Africa: One strategy for addressing teaching and learning challenges. International Journal of Education and Development using Information and Communication Technology 3(4): 131-142.

Jonassen, D. H. 1999. Designing constructivist learning environments. In Instructional design theories and models: A new paradigm of instructional theory, Volume II, ed. C. M. Reigeluth. Mahwah, NJ: Lawrence Erlbaum Associates.

Kok, I. and A. S. Blignaut. 2008. Introducing developing teacher-students in a developing context to eportfolios. Paper presented at the eLearning Forum, 19-20 January 2009. http://www.eifel.org/ publications/proceedings/ilf09/ilearning-forum-2009-proceedings.pdf (Accessed 10 October 2017).

Leow, F. T., M. Neo and S. H. Hew. 2016. Investigating the key attributes to enhance students' learning experience in 21st century class environment. Electronic Journal of e-Learning 14(4): 244-256.

Lin, Q. 2008. Preservice teachers' learning experiences of constructing e-portfolios online. The Internet and Higher Education 11(3-4): 194-200.

Little, D. 2009. Language scholar autonomy and the European Language Portfolio: Two L2 English examples. Language Teaching 42(2): 222-233.

Lorenzo, G. and J. Ittelson. 2005. Demonstrating and assessing scholar learning with e-portfolios. Educause Learning Initiative 3: 1-19.

Mason, R., C. Pegler and M. Weller. 2004. E-portfolios: An assessment tool for online courses. British Journal of Education Technology 35(6): 717-727.

McDermott, K. and S. Gallagher. 2011. Integration of e-portfolios into cooperative education: Lessons learnt. Asia Pacific Journal of Cooperative Education 12(2): 95-101.

McKenna, G., G. Baxter and T. Hainey. 2017. E-portfolios and personal development: A higher education perspective. Journal of Applied Research in Higher Education 9(1): 147-171. 
McLaughlin, J. E., M. T. Roth, D. M. Glatt, N. Gharkholonarehe, C. A. Davidson, L. M. Griffin and R. J. Mumper. 2014. The flipped classroom: A course redesign to foster learning and engagement in a health professions school. Academic Medicine 89(2): 236-243.

Mehtap, C., M. Gulcan and G.-T. Belgin. 2010. How portfolio use affects scholars' learning and their attitudes towards 6th-grade science lesson. International Online Journal of Educational Sciences, 2(2): $362-377$.

Meyer, E., P. Abrami, A. Wade, O. Aslan and L. Deault. 2010. Improving literacy and metacognition with electronic portfolios: Teaching and learning with ePEARL.Computers \& Education 55(1): 84-91.

Mozelius, P., T. Serey and R. D. Escobar. 2016. ePortfolios for entrepreneurs / ePortafolios para Emprendadoras - Design and development of an online distance course.

Nicolaidou, I. 2013. E-portfolios supporting primary students' writing performance and peer feedback. Computers and Education 68(2013): 404-415.

Nudelman, G. R. 2017. Engineering identity: Analysing e-portfolios in a professional communications course. South African Journal of Higher Education 31(2): 211-225.

O'keeffe, M. and R. Donnelly. 2013. Exploration of e-portfolios for adding value and deepening learning in contemporary higher education. International Journal of ePortfolio 3(1): 1-11.

Parker, M., A. Ndoye and A. D. Ritzhaupt. 2012. Qualitative analysis of scholar perceptions of eportfolios in teacher education. International Society for Technology in Education. Journal of Digital Learning in Teacher Education 28(3): 99-107.

Pegrum, M. and G. Oakley. 2017. The changing landscape of e-portfolios: Reflections on 5 years of implementing e-portfolios in pre-service teacher education. In E-Portfolios in higher education, 21-34. Springer Singapore.

Pintrich, P. R. 2000. The role of goal orientation in self-regulated learning, 451-502. San Diego, CA: Academic Press.

Raybourn, E. and Regan, D. 2011. Exploring e-portfolios and independent open scholar models: towards Army Learning Concept 2015. Proceedings. Paper presented at Interservice/Industry Training, Simulation and Education Conference held from 28 November to 2 December in Florida, USA. p. $1-8$.

Reese, M., and Levy, R. 2009. Assessing the future: E-portfolio trends, uses, and options in higher education. Center for Applied Research-Research Bulletin. 2009(4): 1-12.

Siemens, G., A. Mcauley, B. Stewart and G. Cormier. 2010. The MOOC model for digital practice. http://www.elearnspace.org/Articles/MOOC_Final.pdf (Accessed 12 April 2015).

Strampel, K., R. Sibson and S. Main. 2017. Professional development to support the embedding of eportfolios in hgher education programs. In ePortfolios in Australian Universities, 33-46. Springer, Singapore.

Vasinda, V. J. R. S. and J. A. R. L. Haas. 2017. The use of ePortfolios in teacher education programs to support reflective practitioners in a digital world.Deconstructing the education-industrial complex in the digital age, 104.

Yastibas, A. E. and S. Cepik. 2015. Teachers' attitudes toward the use of e-portfolios in speaking classes in English language teaching and learning. Procedia-Social and Behavioral Sciences 176: 514 525 .

Yang, M., M. Tai and C. P. Lim. 2016. The role of e-portfolios in supporting productive learning. British Journal of Educational Technology 47(6): 1276-1286.

Yusuf, J. and P. Tuisawau. 2011. Scholars' attitudes towards the use of e-portfolios: Experiences from the University of the South Pacific. Malaysian Journal of Education Technology 11(4): 31-41.

Zimmerman, B. 1989. A social cognitive view of self-regulated academic learning. Journal of Educational Psychology 81(3): 329-339. 